\title{
PENGARUH MODEL PEMBELAJARAN PROBLEM BASED $L E A R N I N G$ TERHADAP HASIL BELAJAR SISWA PADA MATERI POKOK BESARAN DAN SATUAN DI KELAS X SEMESTER I SMA SWASTA MUHAMMADIYAH 8 KISARAN T.P 2014/2015
}

\author{
Rizky Ari Fahmi Saragih dan Abd. Hakim S \\ Jurusan Fisika FMIPA Universitas Negeri Medan \\ ari.fahmi@gmail.com
}

\begin{abstract}
ABSTRAK
Penelitian ini bertujuan untuk mengetahui pengaruh model pembelajaran Problem Based Learning terhadaphasil belajar fisika siswa pada materi pokok Besaran dan Satuan di kelas X semester I SMA Swasta Muhammadiyah 8 Kisaran T.P 2014/2015. Jenis penelitian ini adalah quasi experiment. Populasi dalam penelitian adalah seluruh siswa kelas X Semester I SMA Swasta Muhammadiyah 8 Kisaran yang terdiri dari 5 kelas. Pengambilan sampel dilakukan dengan cara cluster randomsampling dengan mengambil 2 kelas dari 5 kelas secara acak yaitu kelas X-1 sebagai kelas eksperimen dan kelas X-2 sebagai kelas kontrol yang masing-masing berjumlah 33 orang. Instrumen yang digunakan untuk mengetahui hasil belajar siswa adalah tes hasil belajar dalam bentuk pilihan berganda dengan jumlah 20 soal. Berdasarkan analisis data diperoleh hasil pretes dan postes kedua kelas yang berdistribusi normal dan berasal dari kelompok yang homogen. Hasil postes diperoleh rata-rata kelas eksperimen yang menggunakan model pembelajaran problem based learning75,30 dan kelas kontrol yang menggunakan pembelajaran konvensional 63,63. Dari hasil pengamatan yang dilakukan oleh observer diperoleh rata-rata aktivitas siswa pada pertemuan ke I sebesar 54,38\%, pertemuan ke II $=75,63 \%$. Berdasarkan hasil uji t diperoleh ada perbedaan yang signifikan akibat pengaruh model pembelajaran problem based learning terhadap hasil belajar siswa pada materi pokok Besaran dan Satuan di kelas X semester I SMA Swasta Muhammadiyah 8 Kisaran T.P 2014/2015.
\end{abstract}

Kata Kunci : pembelajaran berdasarkan masalah, hasil belajar fisika, aktivitas

\section{PENDAHULUAN}

Pendidikan merupakan suatu upaya untuk meningkatkan kualitas setiap individu secara langsung atau tidak langsung dipersiapkan untuk menopang dan mengikuti laju perkembangan ilmu pengetahuan dan teknologi dalam rangka mensukseskan pembangunan sejalan dengan tuntutan kebutuhan. Pendidikan memiliki pengaruh yang besar bagi pembangunan di setiap Negara misalnya saja pendidikan di sekolah dalam pelajaran fisika. Shabri (2013) menyatakan bahwa kualitas pendidikan di Indonesia masih rendah, dapat dilihat dari beberapa indikator.
Pertama, Kementrian pendidikan nasional melaporkan bahwa dari 146.052 SD di Indonesia, hanya 8 sekolah yang mendapat pengakuan dunia, dari 20.918 SMP, hanya 8 sekolah yang mendapat pengakuan dunia, dan dari 8.036 SMA, hanya 7 sekolah yang mendapat pengakuan dunia. Kedua, dibandingkan dengan Negara Asia lain, menurut survey Political and Economic Risk Consultant, kualitas pendidikan di Indonesia berada pada urutan ke-12 dari 12 negara.

Rendahnya mutu pendidikan juga terlihat pada saat pelaksanaan PPLT 2012 di SMP Negeri 5 Pemantang 
Siantar. Berdasarkan pengamatan penulis, siswa tidak tertarik belajar fisika. Siswa berpendapat bahwa fisika penuh dengan rumus-rumus yang membingungkan. Guru fisika masih menggunakan proses pembelajaran yang berpusat pada guru karena guru jarang melibatkan siswa dalam pembelajaran dan hanya menekankan siswa untuk menghapal rumus-rumus tanpa menekankan konsep fisika dan menerapkannya, sehingga kemampuan siswa dalam memahami dan menerapkan konsep fisika kurang yang menyebabkan nilai hasil belajar juga rendah. Pembelajaran yang disampaikan sangat monoton, sehingga kebanyakan aktivitas siswa dalam memecahkan suatu masalah hanya dengan menghafal rumus yang ada didalam bukunya tanpa di analisa terlebih dahulu. Aktivitas seperti kegiatan yang menyebabkan sikap ilmiah siswa dalam mengikuti pembelajaran kurang berkembang dengan baik.

Berdasarkan hasil wawancara peneliti dengan salah satu guru fisika SMA SWASTA Muhamaddiyah 8 Kisaran, beliau mengatakan bahwa nilai rata-rata fisika siswa adalah 63 . Hasil belajar ini masih di bawah KKM (Kriteria Ketuntasan Minimal) yaitu 70. Ketika diwawancara lebih lanjut ternyata pembelajaran yang sering digunakan adalah konvensional dengan metode ceramah, diskusi, mencatat dan mengerjakan soal.

Berdasarkan uraian dari penelitian di atas, jelaslah bahwa metode dan model pembelajaran mempengaruhi suasana dan hasil belajar siswa. Guru yang mengajar dengan model pembelajaran yang kurang menarik dapat menyebabkan siswa menjadi bosan, pasif, dan tidak kreatif. Guru dituntut untuk menggunakan model pembelajaran yang disesuaikan dengan kondisi dan situasi belajar agar tujuan akhir belajar dapat tercapai tepat..
Model pembelajaran berbasis masalah (problem based learning, PBL)) merupakan salah satu model yang menantang siswa untuk mencari solusi suatu masalah dari dunia nyata yang dapat diselesaikan secara berkelompok. Moreles-mann dan Kaitell dalam Setyorini, dkk (2011-54) mengemukakan bahwa manfaat penggunaan PBL dapat meningkatkan pembelajaran otonom, berpikir kritis, pemecahan masalah dan keahlian dalam berkomunikasi.

Pembelajaran problem based learning menuntut siswa untuk melakukan pemecahan masalahmasalah yang disajikan dengan cara menggali informasi sebanyakbanyaknya, kemudian menganalisis dan mencari solusi dari permasalahan yang ada. Pembelajaran problem based learning mengorientasikan siswa kepada masalah, multi disiplin, menuntut kerjasama dalam penelitian, dan menghasilkan karya.

Peneliti juga melihat hasil penelitian sebelumnya yang dilakukan oleh Setyorini, dkk (2011:53) mengatakan bahwa, Hasil penelitian berupa kemampuan berpikir kritis, aspek afektif dan aspek psikomotorik dalam pembelajaran yang menggunakan model PBL. Hasil kemampuan berpikir kritis siswa mengalami peningkatan secara signifikan antara kelas eksperimen yang menggunakan model PBL dan kelas kontrol yang menerapkan model DI dengan metode ceramah. Model pembelajaran $\mathrm{PBL}$ mengajak siswa secara langsung aktif terlibat dalam proses pembelajaran. Kelas kontrol yang menggunakan model DI dengan metode ceramah dimana model tersebut sering diterapkan pada saat pembelajaran berlangsung. Hasil afektif siswa setelah diterapkan model PBL pada sub pokok bahasan GLBB antara kelas eksperimen dengan kelas kontrol mengalami peningkatan. Meningkatnya aspek afektif dikarenakan penciptaan lingkungan 
belajar yang barn di dalam kelas melalui PBL membangkitkan sikap yang baik bagi siswa. Hasil psikomotorik siswa setelah diterapkan model PBL pada sub pokok bahasan GLBB antara kelas eksperimen dengan kelas kontrol, mengalami peningkatan. Meningkatnya, aspek psikomotorik erat kaitannya dengan keaktifan siswa ketika, proses pembelajaran berlangsung.

Penelitian Husna (2012:43) mengatakan bahwa Hasil penelitian menunjukan bahwa, kelas eksperimen dengan model PBL lebih tinggi dari pada kelas kontrol dengan pembelajaran konvensional dengan perbedaan yang signifikan ketika siswa diajarkan dengan model pembelajaran Problem Based Learning. Saran dari Lailatul Husna, bagi mahasiswa, calon guru yang akan meneliti lebih lanjut dengan model pembelajaran Problem Based learning agar lebih memahami dengan jelas masalah yang diberikan oleh siswa ataupun masalah yang ditawarkan kepada siswa serta lebih menguasai tahapan dalam model pembelajaran ini.

Berdasarkan latar belakang di atas maka penulis tertarik untuk melakukan penelitian dengan tujuan untuk melihat pengaruh model problem based learning terhadap hasil belajar siswa pada materi pada materi pokok Besaran dan Satuan di kelas X semester I SMA Swasta Muhammadiyah 8 Kisaran T.P 2014/2015.

\section{METODE PENELITIAN}

Populasi dalam penelitian ini adalah seluruh siswa kelas $\mathrm{X}$ semester II SMA Swasta Muhammadiyah 8 Kisaran pada tahun Ajaran 2013 / 2014 yang terdiri dari 5 kelas.

Sampel dalam penelitian ini terdiri dari dua kelas yaitu kelas eksperimen dan kelas kontrol yang diambil dengan teknik cluster random sampling. Kelas eksperimen diajar dengan menggunakan model pembelajaran problem based learning kelas kontrol diajar dengan menggunakan pembelajaran konvensional. Desain penelitian yang digunakan adalah control group pretest-posttest yang ditunjukkan oleh Tabel 1.

Tabel 1. Control Group Pretest-Posttest Design (Arikunto, 2012)

\begin{tabular}{|l|c|c|c|}
\hline \multicolumn{1}{|c|}{ Kelas } & Pretes & $\begin{array}{c}\text { Perlak } \\
\text { uan }\end{array}$ & $\begin{array}{c}\text { Poste } \\
\text { s }\end{array}$ \\
\hline $\begin{array}{l}\text { Eksperim } \\
\text { en }\end{array}$ & $O_{1}$ & $X_{1}$ & $O_{2}$ \\
\hline Kontrol & $O_{1}$ & $X_{2}$ & $O_{2}$ \\
\hline
\end{tabular}

Keterangan:

$O_{1}=$ pretes

$X_{1}=$ model problem based learning

$\mathrm{O}_{2}=$ postes

$X_{2}=$ pembelajaran konvensional

Metode pengumpulan data meliputi wawancara kepada salah satu guru di sekolah yang bersangkutan untuk mengetahui bagaimana guru melaksanakan proses pembelajaran di kelas.

Teknik analisis yang digunakan untuk menentukan pengaruh model problem based learning terhadap hasil belajar siswa adalah melakukan uji hipotesis dengan menggunakan uji beda (uji $t$ ) dengan syarat data harus berdistribusi normal dan bersifat homogen (Sudjana, 2005). Teknik analisis ini dilakukan pada data tes hasil belajar yang diperoleh yaitu data pretes dan postes.

Apabila hasil pretes kedua kelas memiliki kesamaan rata-rata, berarti kemampuan awal kelas eksperimen sama dengan kemampuan awal siswa pada kelas kontrol. Apabila hasil postes kelas eksperimen yang menerapkan model problem based learning lebih tinggi dari kelas kontrol dengan pembelajaran konvensional, berarti ada perbedaan hasil belajar 
yang signifikan akibat penerapan model problem based learning.

\section{HASIL DAN PEMBAHASAN Hasil Penelitian}

Penelitian diawali dengan pemberian pretes pada kelas eksperimen dan kelas kontroluntuk mengetahui kemampuan awal siswa. Dari hasil pretes diperoleh nilai ratarata pretes siswa kelas eksperimen sebesar 39.69 dan rata-rata pretes siswa kelas kontrol sebesar 39,84. Ternyata dari pengujian nilai pretes kelas eksperimen dan kontrol diperoleh kedua kelas memiliki kemampuan awal yang sama dan kedua kelas homogen. Secara ringkas hasil pretes kedua kelompok dapat dilihat pada Gambar 1.

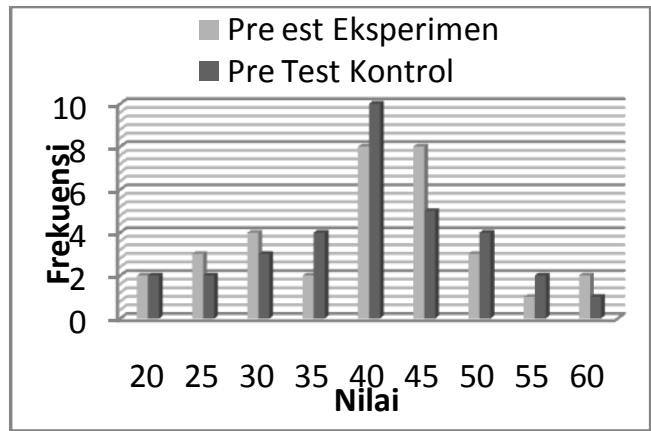

Gambar 1 Data pretes kelas eksperimen dan kontrol

Perbandingan kemampuan kognitif siswa untuk data pretes berdasarkan taksonomi Bloom, yang memiliki 6 tingkat kemampuan, yaitu dari C1 - C6, seperti ditunjukkan pada Gambar 2.

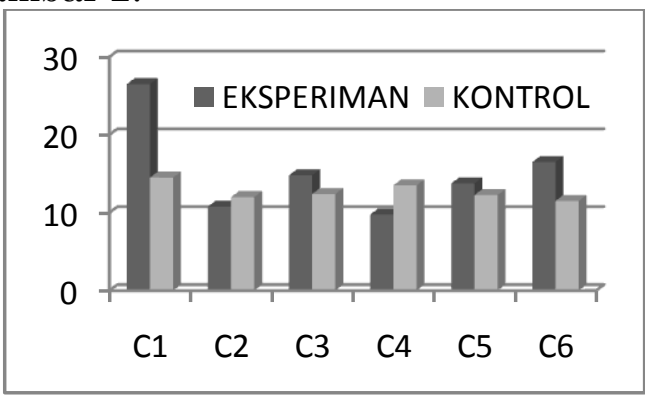

Gambar 2. Diagram batang kognitif pretes siswa
Setelah kedua sampel diterapkan perlakuan yang berbeda di mana pada kelas eksperimen diterapkan model pembelajaran problem based learningdan pada kelas kontrol diterapkan pembelajaran konvensional diperoleh hasil postes kedua kelas seperti ditunjukkan pada Gambar 3.

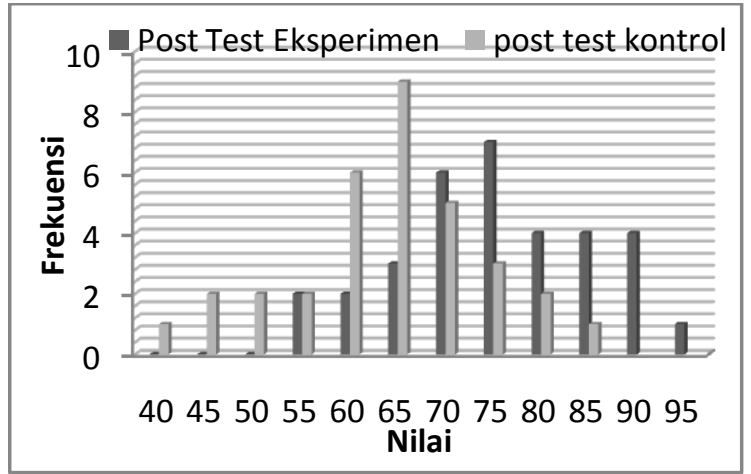

Gambar 3. Data Postes Kelas Eksperimen dan Kelas Kontrol

Perbandingan kemampuan kognitif siswa untuk data postes berdasarkan taksonomi Bloom, yang memiliki 6 tingkat kemampuan, yaitu dari C1 - C6, seperti ditunjukkan pada Gambar 4.

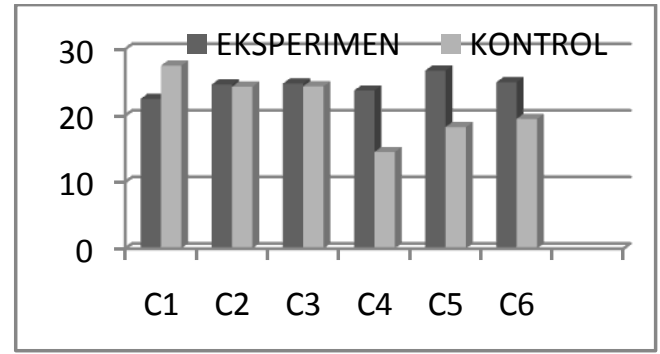

Gambar 4. Diagram batang kognitif postes siswa

Berdasarkan diagram batang kognitif postes siswa terdapat perbedaan hasil belajar siswa akibat pengaruh model pembelajaran problem based learning (kelas eksperimen) dengan pembelajaran Konvensional (kelas kontrol), hal ini menunjukkan bahwa penerapan model pembelajaran 
problem based learningbaik untuk diterapkan.

\section{Pembahasan}

Hasil penelitian menunjukkan bahwa ada pengaruh yang signifikan antara hasil belajar siswa dengan model pembelajaran Problem Based Learning dan model pembelajaran konvensional pada maeri pokok besaran dan satuan kelas X semester I di SMA Swasta Muhammadiyah 8 Kisaran T.A 2014/2015. Hal ini diperkuat dengan perolehan nilai rata-rata pretes siswa dikelas eksperimen sebesar 39,69 dan nilai rata-rata postes sebesar 75,30 . Sedangkan di kelas kontrol diperoleh nilai rata-rata pretes siswa sebesar 39,84 dan nilai rata-rata postes sebesar 63,63 .

Berdasarkan gambar 4.2 rata rata skor kognitif pretes siswa pada $\mathrm{C} 1$ (Pengetahuan) adalah kemampuan yang paling banyak diperoleh siswa, jika dilihat lebih rinci, semakin tinggi tingkat kemampuan pada taksonomi bloom.

Berdasarkan Gambar 4, dapat diketahui bahwa kemampuan kognitif postes siswa di kelas eksperimen menggunakan model problem based learning lebih tinggi daripada kemampuan kognitif siswa di kelas kontrol.

Modelproblem based learning memberikan pengaruh terhadap hasil belajar pada aspek kognitif karena model problem based learningmembuat siswa dapat memperoleh pengetahuan dari proses penyelidikan autentik melalui masalah yang disajikan pada fase pertama.

Kelas eksperimen banyak mengalami perubahan tingkah laku selama pembelajaran. Hal ini disebabkan karena siswa kelas eksperimen memperoleh pengetahuannya dari berbagai sumber, yaitu saat mereka merumuskan hipotesis, mereka dapat mengajukan pemikiran awalnya tentang permasalahan yang disajikan pada pembelajaran tersebut.

Siswa yang diberi pelajaran dengan menggunakan pembelajaran konvensional hanya memperoleh pengetahuan berdasarkan apa yang dikatakan oleh guru. Berdasarkan apa yang diamati oleh peneliti, siswa kelas kontrol sepenuhnya bergantung dengan yang diajarkan oleh guru pada saat pembelajaran.

Berdasarkan uraian diatas dapat disimpulkan bahwa model problem based learning dapat meningkatkan keterampilan siswa dan rasa percaya diri siswa. Hal ini didukung oleh Arends (2012) yang menyatakan bahwa pembelajaran berdasarkan masalah merupakan suatu pendekatan pembelajaran di mana siswa mengerjakan permasalahan yang autentik dengan maksud untuk menyusun pengetahuan mereka sendiri, mengembangkan inkuiri dan keterampilan berpikir tingkat lebih tinggi, mengembangkan kemandirian dan percaya diri.

Berdasarkan hasil penelitian yang dilakukan, terdapat perbedaan hasil belajar dan hasil observasi aktivitas antara kelas eksperimen dengan kelas kontrol. Hasil penelitian menunjukkan bahwa ada pengaruh yang signifikan model problem based learning terhadap hasil belajar siswa pada materi pokok Besaran dan Satuan di kelas X semester I SMA Swasta Muhammadiyah 8 Kisaran T.P 2014/2015

\section{KESIMPULAN DAN SARAN \\ Kesimpulan}

Adapun kesimpulan yang diperoleh adalah sebagai berikut:

Hasil belajar siswa kelas eksperimen dengan menerapkan model pembelajaran problem based learning pada materi pokok besaran dan satuandi kelas $\mathrm{X}$ semester I SMA Swasta Muhammadiyah 8 Kisaran Tahun Pelajaran 2014/2015 dengan 
rata-rata pretes sebesar 39,67 dan ratarata postes siswa sebesar 75,30 .

Hasil belajar siswa kelas kontrol dengan menerapkan pembelajaran konvensional pada materi besaran dan satuan di kelas Xsemester I SMA Swasta Muhammadiyah 8 Kisaran Tahun Pelajaran 2014/2015dengan rata-rata pretes sebesar 39,84 dan ratarata postes siswa sebesar 63,63. Berdasarkan hasil uji t diperoleh ada perbedaan yang signifikan akibat pengaruh model pembelajaran problem based learning terhadap hasil belajar siswa pada materi pokok Besaran dan Satuan di kelas X semester I SMA Swasta Muhammadiyah 8 Kisaran T.P 2014/2015.

\section{Saran}

Bagi mahasiswa calon guru hendaknya lebih memahami model pembelajaran berdasarkan masalah sebagai salah satu upaya untuk mengaktifkan siswa belajar, menambah kreativitas dan semangat belajar siswa, serta meningkatkan hasil belajar siswa.

Kepada peneliti selanjutnya yang ingin meneliti tentang model pembelajaran berdasarkan masalah lebih lanjut, disarankan untuk lebih memperhatikan efisiensi waktu pada tahap "mengembangkan dan menyajikan hasil karya", karena pada tahap ini hampir semua siswa ingin menampilkan hasil diskusi mereka.

Bagi mahasiswa calon guru yang ingin melakukan penelitian yang sama sebaiknya lebih memahami dengan jelas tahap-tahap model pembelajaran problem based learning agar aktivitas dan hasil belajar yang diharapkan dapat tercapai.

\section{DAFTAR PUSTAKA}

Arends, R., (2012), Learning to Teach Ninth Edition, Yogyakarta: Pustaka Pelajar

Arikunto, S. 2012. Dasar- Dasar Evaluasi Pendidikan. Jakarta : Bumi Aksara.

Husna, L. 2012. Pengaruh Model Pembelajaran Berdasarkan Masalah Terhadap Hasil Belajar Siswa Pada Materi Pokok Listrik Dinamis kelas $X$ Semester $2 \mathrm{Di}$ SMA Negeri 1 Labuhan Deli T.A 2011/2012., Skripsi, Medan: FMIPA UNIMED.

Setyorini, dkk., 2011. Penerapan Model Problem Based Learning untuk Meningkatkan Kemampuan Berpikir Kritis Siswa SMP. Jurnal Pendidikan Fisika Indonesia (JPFI)

Sudjana. 2005. Metode Statistika. Bandung: Tarsito. 